\title{
Negative pressure pulmonary oedema: an alarming complication of general anaesthesia in a young healthy male
}

\author{
Edema pulmonary por presión negative: una complicación grave \\ de la anestesia general en un paciente joven
}

Negative pressure pulmonary oedema is a rare but potentially harmful event ${ }^{1,3}$. The mechanisms of this pulmonary injury are not totally understood. It is believed that airway obstruction, as caused by laryngospasm after extubation, combined with the attempt of a forced inspiring effort, produce a negative intrathoracic pressure, increasing the venous return with a consequent rise of the hydrostatic pressure, ultimately leading to a leakage of fluid to the extracellular compartment. Nevertheless, it is possible that other factors may contribute to this condition, including hypoxia, cardiogenic and neurogenic mechanisms ${ }^{2}$.

We present the case of a healthy 20-years-old male, who underwent a deferred left clavicle osteosynthesis. Only a few minutes after extubation and awakening, the patient developed irritative cough and marked dyspnoea. He did not show clinical improvement after increasing oxygen supply and bronchodilators. After medical observation and a plain chest radiograph ruled out mechanical complications such as pneumothorax, the diagnostic possibility thought of was a pulmonary embolism. The patient was then transferred to our hospital for further evaluation.

A thoracic Computed Tomography (CT) scan with angiographic contrast was performed (figure 1), ruling out pulmonary embolism but revealing multiple areas of ground glass aspect and alveolar filling with centrilobular distribution, suggesting oedema or alveolar haemorrhage. ECG and bedside echocardiogram were perfectly normal, haemoglobin remained normal, blood gas only showed hypoxemia with normal $\mathrm{pH}$, carbon dioxide, bicarbonate and lactates. No signs of shock or any other organ failure were present. At first the patient was treated with hydrocortisone, clemastine and nebulized ipratropium and salbutamol, beside supplementary oxygen, with no need for positive pressure ventilation.

The symptoms began to improve within the first hour (the patient was asymptomatic with oxygen therapy). After the assumption of this diagnostic possibility he remained only in observation, with complete withdrawal of oxygen therapy the next day, 12 hours after admission, the patient being at that point completely asymptomatic. The patient nevertheless remained under observation for another day, with no further complications. He was discharged after a control CT scan showing radiologic improvement.

This case highlights the need to be aware of this diagnosis, that is usually self-limited but can be life-threatening and require specific treatment.
Figure 1: CT scan showing multiple areas of ground glass aspect and alveolar filling with centrilobular distribution.

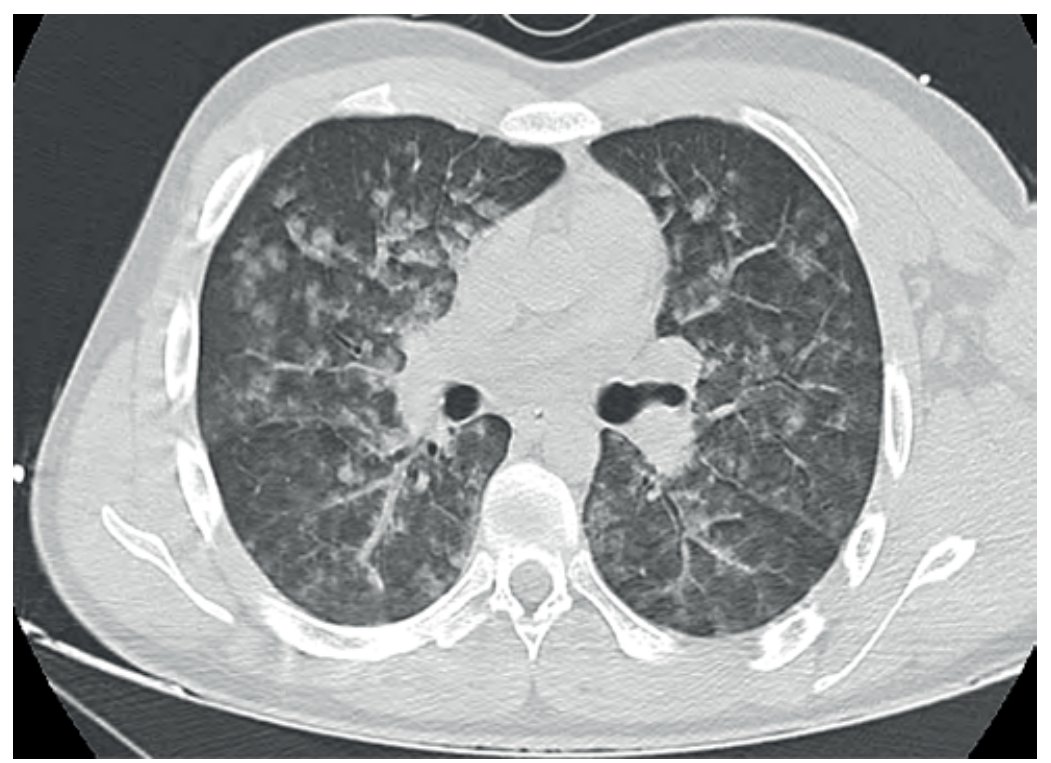

Take-home messages:

- Negative pressure pulmonary oedema is a rare complication of ventilator support.

- It may be self-limited but severe cases may need directed treatment.

- Rapid recognition is essential to provide the best care to the patient, with adequate treatment and preventing the use of unnecessary invasive measures.

\section{References}

1. Kapoor M. Negative pressure pulmonary oedema. Indian Journal of Anaesthesia. 2011;55(1):10.

2. Bhaskar B, Fraser J. Negative pressure pulmonary edema revisited: Pathophysiology and review of management. Saudi Journal of Anaesthesia. 2011;5(3):308.

3. Patton WC, Baker CL Jr. Prevalence of negative-pressure pulmonary edema at an orthopaedic hospital. J South Orthop Assoc. 2000 Winter;9(4):248-53.

\section{Diagnosis}

\section{Negative pressure pulmonary oedema}

Luis M. Afonso, Marta Pereira

Serviço de Medicina Interna. Hospital Pedro Hispano. Unidade Local de Saúde de Matosinhos

Correspondencia: Imdsafonso@gmail. com

Como citar este artículo: Afonso LM, Pereira $M$

Negative pressure pulmonary oedema: an alarming complication of general anaesthesia in a young healthy male. Galicia Clin 2016; 77 (4): 189

Recibido: 11/01/16 ; Aceptado: 05/03/16 